\title{
DNA ploidy patterns and cytokinetics of non-Hodgkin's lymphoma
}

\author{
S K JUNEJA, ${ }^{*}$ I A COOPER, ${ }^{*}$ G S HODGSON, $\dagger$ M M WOLF, ${ }^{*}$ J C DING* \\ P N J IRONSIDE, $\ddagger$ R J S THOMAS, ${ }^{*}$ J D PARKIN§ \\ From the *Haematology Research Unit, the $\dagger$ Biological Research Unit, and the $\ddagger$ Department of Pathology, \\ Cancer Institute, Melbourne, and the §Department of Haematology, Repatriation General Hospital, Heidelberg, \\ Victoria, Australia
}

SUMMARY Flow cytometry studies for cellular DNA analysis were performed in 115 cases of non-Hodgkin's lymphoma, 53 of which had not received any prior chemotherapy or radiotherapy. DNA content was measured in ethanol fixed cells stained with chromomycin A3. According to the criteria of the International Working Formulation there were 43 low grade, 58 intermediate grade, and eight high grade lymphomas; six cases were in the miscellaneous group. Seventy seven $(67 \%)$ had only diploid DNA content. Thirty eight (33\%) showed DNA aneuploidy; 20 of these had been previously treated with chemotherapy or radiotherapy, or both. DNA aneuploidy was seen as hyperdiploidy in all cases except one, and it varied from slightly hyperdiploid to tetraploid. The incidence of aneuploidy increased significantly with increasing histological grade $(p=0.0002)$ and was not related to previous treatment. The low, intermediate, and high grade lymphomas had $14 \%$ (six of 43 ), $47 \%$ (27 of 58), and $62.5 \%$ (five of eight) cases, respectively, that showed DNA aneuploidy. The percentage of cells in $\mathrm{S}$ phase increased significantly with a higher histological grade $(\mathrm{p}<0.0001)$. The median $\mathrm{S}$ fraction in the low, intermediate, and high grade lymphomas was $1.0(0.5$ to 10$) \% 4(0.4$ to 35$) \%$, and $27(4.6-56) \%$, respectively.

There is a significant correlation between histological grade and $\mathbf{S}$ fraction and the presence or absence of aneuploidy. There is heterogeneity, however, within both histological grade and a histological subtype.

Classification of non-Hodgkin's lymphoma on the basis of morphology alone may not provide adequate information about the biological behaviour. A more complete picture can be obtained by supplementing morphology with immunological, cytokinetic, cytogenetic, and other biological markers. Differences in DNA ploidy have recently been reported within various tumours, including non-Hodgkin's lymphoma, and these differences may have prognostic implications. ${ }^{1-4}$ In non-Hodgkin's lymphoma differences in the $\mathrm{S}$ fraction of the cell cycle and RNA content have also been reported and these seem to influence survival. $^{5-9}$ This study was carried out to ascertain the incidence of DNA aneuploidy, determined by flow cytometry, and to correlate aneuploidy and the percentage of S phase cells within the various histological types of non-Hodgkin's lymphoma.

Accepted for publication 9 April 1986

\section{Material and methods}

Fresh lymph node $(n=116)$, spleen $(n=14)$, or affected extranodal lymphoid tissue $(n=16)$ specimens were obtained by surgical excision. Affected peripheral blood and bone marrow were studied in nine and five cases, respectively. In all cases routine histological sections and cytological preparations were available for morphological diagnosis. NonHodgkin's lymphomas were classified according to the International Working Formulation. ${ }^{10}$

Cell suspensions were prepared by gently pressing the minced lymph node through a stainless steel mesh into phosphate buffered saline at pH 7.2. Mononuclear cell suspensions were prepared from blood and marrow on a ficoll and hypaque gradient. Viability was determined by use of trypan blue and was $80 \%$ or greater in all cases.

Tritiated thymidine labelling was performed on an aliquot of the sample containing $2 \times 10^{6}$ cells in $5 \mathrm{ml}$ 
Table Distribution of DNA aneuploidy according to histological subtype (figures in parentheses are numbers $\%$ aneuploid)

\begin{tabular}{llcc}
\hline Histologic subtype & Previously treated $^{*}$ & Previously untreated & Total $^{*}$ \\
\hline Low grade: & & & \\
Small lymphocytic including CLL† & $0 / 5^{*}(0)$ & $1 / 8(13)$ & $1 / 13(8)$ \\
Follicular, small cleaved cell & $3 / 14(21)$ & $1 / 9(10)$ & $4 / 20(17)$ \\
Follicular, mixed cell & $1 / 3(33)$ & $0 / 3$ & $1 / 6(17)$ \\
& $4 / 22(18)$ & $2 / 21(10)$ & $6 / 43(14)$ \\
Intermediate grade: & $0 / 0$ & $0 / 1$ & $0 / 1$ \\
Follicular, large cell & $5 / 13(39)$ & $1 / 8(13)$ & $6 / 21(29)$ \\
Diffuse, small cleaved cell & $3 / 7(43)$ & $2 / 5(40)$ & $5 / 12(42)$ \\
Diffuse, mixed cell & $9 / 14(64)$ & $7 / 10(70)$ & $16 / 24(67)$ \\
Diffuse, large cell & $17 / 34(50)$ & $10 / 24(42)$ & $27 / 58(47)$ \\
& $2 / 2(100)$ & $1 / 2(50)$ & $3 / 4(75)$ \\
High grade: & $0 / 2$ & $2 / 2(100)$ & $2 / 4(50)$ \\
Immunoblastic & $2 / 4(50)$ & $3 / 4(75)$ & $5 / 8(63)$ \\
Small, non-cleaved & $0 / 3$ & $0 / 3$ & $0 / 6$ \\
Miscellaneous & $23 / 63(37)$ & $15 / 52(29)$ & $38 / 115(33)$ \\
\end{tabular}

* No aneuploid over total.

†CLL Chronic lymphocytic leukaemia.

of RPMI with $10 \%$ fetal calf serum. This was incubated with $\left({ }^{3} \mathrm{H}\right)$ thymidine $(2 \mathrm{uCi} / \mathrm{ml}$; specific activity $5 \mathrm{Ci} / \mathrm{mM}$, Radiochemical Centre, Amersham) for one hour at $37^{\circ} \mathrm{C}$ with slow agitation. The cells were

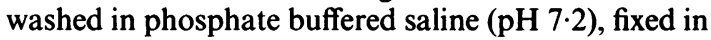
a mixture of three parts of methanol and one part of glacial acetic acid, and smears were made. Autoradiographs were prepared using Kodak NTB2 emulsion and exposed for seven days at $4^{\circ} \mathrm{C}$ before being developed in Kodak D19. The slides were stained with May-Grunwald-Giemsa stain. At least 1000 cells were counted for calculating the percentage of labelled cells (labelling index).

The fresh cell suspensions were fixed in $70 \%$ ethanol and stored at $-20^{\circ} \mathrm{C}$. Before running on the flow cytometer, the sample was thawed, washed in phosphate buffered saline, and stained with chromomycin A3. Nuclei isolated from chicken erythrocytes were used as an internal standard and were prepared according to the method of Taylor et al. ${ }^{11}$ The second standard consisted of mononuclear fractions obtained from blood or normal healthy volunteers for comparison of ploidy and size of the tumour cells. Both the standard cells were fixed in $70 \%$ ethanol and stored at $-20^{\circ} \mathrm{C}$. The median ratio of the DNA content of normal lymphocytes and chicken red cells was $3.01(2 \cdot 82-3 \cdot 14)$. The coefficient of variation (CV) was calculated as the ratio of standard deviation and mean multiplied by 100 . The mean $\mathrm{CV}$ of the diploid peak of all non-Hodgkin's lymphomas was 4.7 (2.8 to $5.9) \%$. The mean CV of normal lymphocytes was 3.5 $(2 \cdot 5-4 \cdot 7) \%$.

A flow cytometer (FCM, Ortho Diagnostic Systems; Westwood, Massachusetts) equipped with a 50 $\mu \mathrm{m}$ diameter nozzle was used for DNA content and light scatter measurements. A $458 \mathrm{~nm}$ argon ion laser line at 150 milliwatts was used for excitation and the fluorescence emission was measured in a $20 \mathrm{~nm}$ band about $530 \mathrm{~nm}$. Cell doublets were discriminated by gating on the bivariate distribution of fluorescence "peak" $v$ area. The doublets display a lower peak fluorescence. The resultant histograms were analysed on a computer (2150 Ortho Diagnostic Systems). The $\mathrm{S}$ phase fractions were determined by the Quicle estimate method (Appendix H, Operator Reference Manual 2150 Computer System, Ortho Diagnostie Systems). With this method, the number of cells in G0 $+\mathrm{Gl}$ can be calculated by doubling the sum of the channels measured from the lower limit (L) to the mean of G0 + G1. Likewise, the percentage of cells in $\mathrm{G} 2+\mathrm{M}$ is twice the sum of cells from the mean of G2 $+\mathrm{M}$ to the upper limit of analysis (U). The number of cells in $S$ phase, therefore, is the sum from $L$ to $U$ minus the cells in G0 + G1 and G2 + M. This method almost always underestimates the percentage of cells in $\mathrm{S}$ phase. The diagnosis of aneuploidy was made only when at least two separate $\mathrm{G} 0 / \mathrm{Gl}$ peaks were shown. ${ }^{12}$ A minimum of 40000 cells were studied in each case.

\section{Results}

One hundred and fifty cases were studied in two years. One hundred and twenty of these were nonHodgkin's lymphoma. Of the remaining 30, 20 showed reactive hyperplasia, four Hodgkin's disease, five metastatic carcinoma, and one granulocytic sarcoma. In five cases of non-Hodgkin's lymphoma cell suspensions could not be obtained because of the presence of dense fibrosis. Thus 115 cases of nonHodgkin's lymphoma were studied for cytokinetic features. Fifty three of these had not received any 
(a)

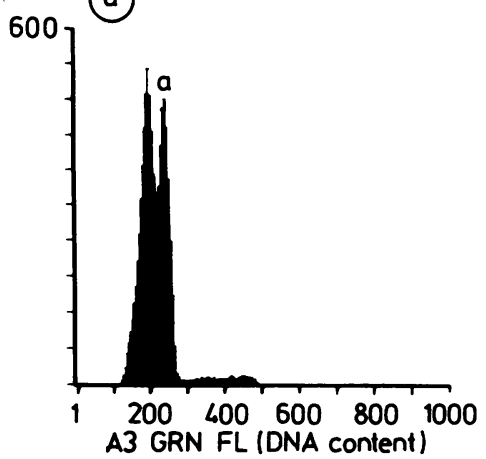

(b)

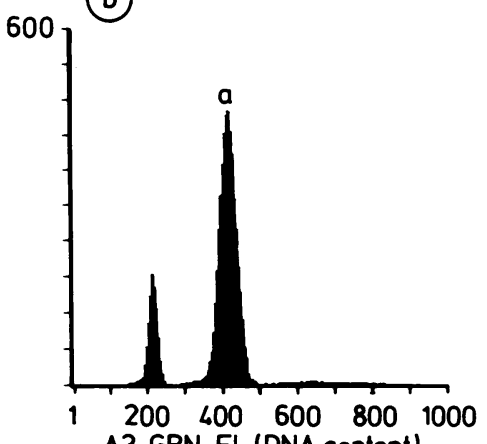

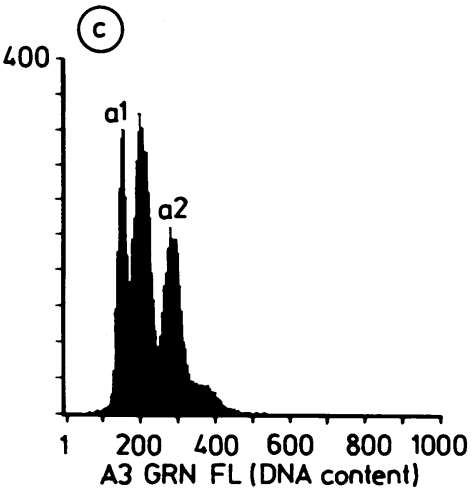

Fig 1 DNA aneuploidy patterns in non-Hodgkin's lymphoma. $a=D N A$ aneuploid peak; $(a)=$ slightly hyperdiploid; (b) = tetraploid; (c) = hypodiploid (al) and hyperdiploid (a2) peaks.

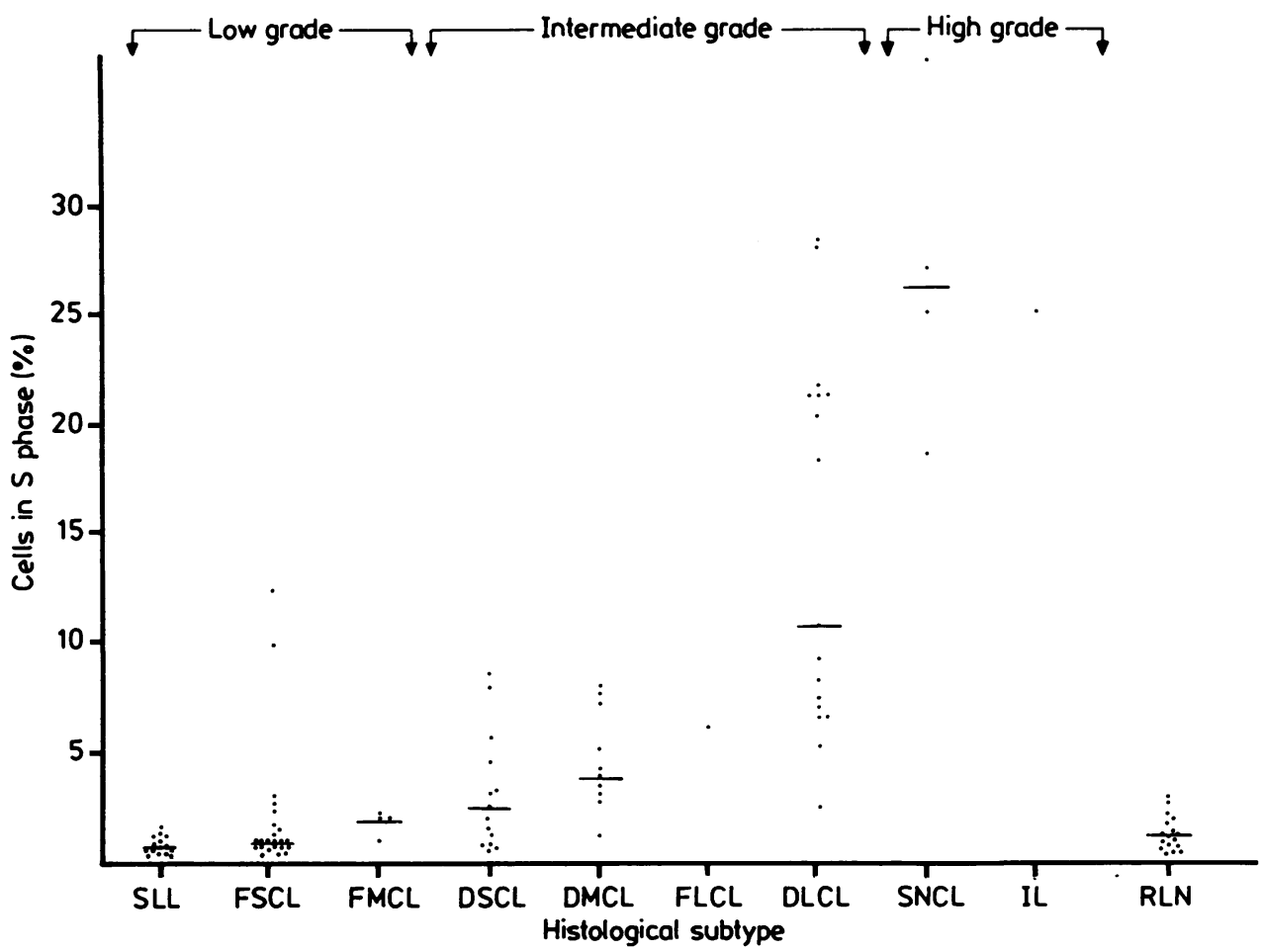

Fig 2 Distribution of S fraction in various histological subtypes of non-Hodgkin's lymphoma. SLL-small lymphocytic lymphoma; $F S C L=$ follicular small cleaved cell lymphoma; $F M C L=$ follicular mixed cell lymphoma; $D S C L=$ diffuse small cleaved cell lymphoma; $D M C L=$ diffuse mixed cell lymphoma; $F L C L$ $=$ follicular large cell lymphoma; $D L C L=$ diffuse large cell lymphoma; $S N C L=$ small non-cleaved cell lymphoma; $I L=$ immunoblastic lymphoma; $R L N=$ reactive lymphadenitis.

prior chemotherapy or radiotherapy while the 62 others had been previously treated. Histologically, there were 43 low grade, 58 intermediate grade, and eight high grade lymphomas. Six cases were in the miscellaneous group.
CYTOMETRY

One hundred and fifteen cases of non-Hodgkin's lymphoma were studied by flow cytometry. Of these, 77 (67\%) had only diploid DNA content (table). The remaining thirty eight $(33 \%)$ cases showed DNA 


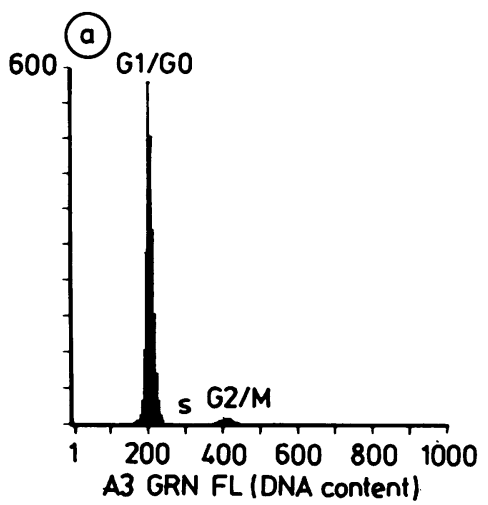

Fig 3 Cell cycle analysis of examples of three grades of non-Hodgkin's lymphoma. $(a)=$ small cell lymphoma with $0 \% S$ fraction, $(b)=$ diffuse large cell lymphoma with $25 \% S$ fraction; $(c)=$ small non-cleaved cell (Burkitt's) lymphoma with $50 \%$ S fraction.

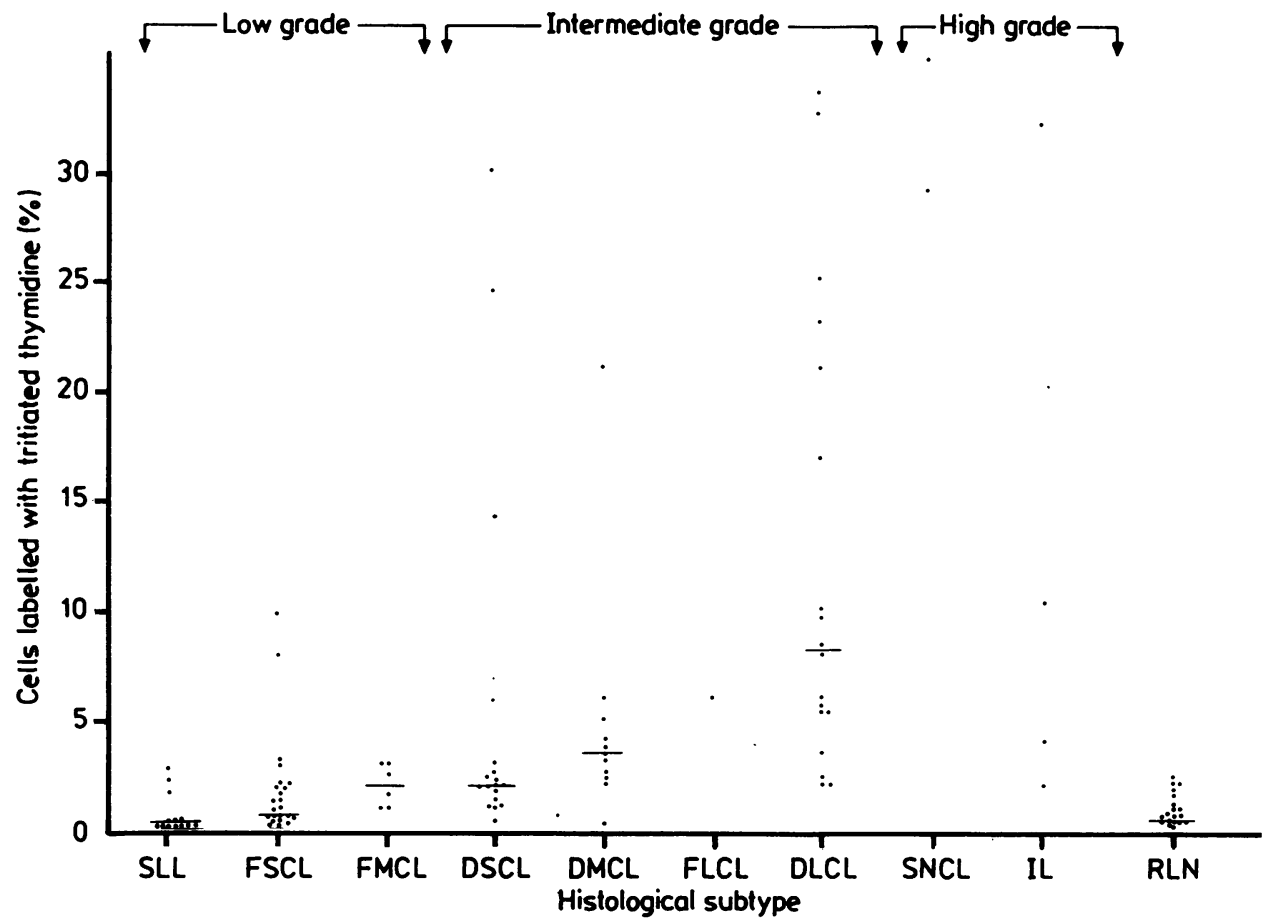

Fig 4 Distribution of labelling index in various histological subtypes of non-Hodgkin's lymphoma. SLL = small lymphocytic lymphoma; $F S C L=$ follicular small cleaved cell lymphoma; $F M C L=$ follicular mixed cell lymphoma; $D S C L=$ diffuse small cleaved cell lymphoma; $D M C L=$ diffused mixed cell lymphoma; $F L C L=$ follicular large cell lymphoma; $D L C L=$ diffuse large cell lymphoma; $S N C L=$ small non-cleaved cell lymphoma; $I L=$ immunoblastic lymphoma; $R L N=$ reactive lymphadenitis.

aneuploidy, shown by the presence of more than one G1/G0 peak. Of the 38 aneuploid cases, 36 were hyperdiploid and two were hypodiploid. The aneuploid population was always accompanied by a population of cells with diploid DNA content. One case had hypodiploid, diploid, and hyperdipoid pop- ulations (fig lc). The hyperdiploidy varied from slightly hyperdiploid to tetraploid (fig 1). In one patient there were populations of cells with two $\stackrel{0}{C}$ different ploidies in the two biopsy specimens from the same site, one diploid and the other having a mixture of diploid and hypodiploid; both specimens were 
classified as diffuse small cleaved cell lymphoma on histological examination. In another patient biopsy specimens from two different sites showed the presence of an aneuploid population in one. The table shows the distribution of DNA aneuploidy in relation to various histological subtypes. The low, intermediate, and high grade lymphomas had $14 \%$ (six of 43 ), $47 \%$ (27 of 58), and 63\% (five of eight) cases, respectively, which showed DNA aneuploidy. These differences in the incidence of aneuploidy were significant $\left(\chi^{2}=14.5 ; p=0.0007\right)$. The incidence of aneuploidy increased significantly the higher the grade $\left(\chi^{2}\right.$ test for trend $\left.=13.5 ; p=0.0002\right)$. Within the intermediate grade category the incidence of aneuploidy increased significantly with increasing large cell component $\left(\chi^{2}\right.$ test for trend $=6 \cdot 7 ; \mathrm{p}=$ 0.03 ). Previous treatment did not influence the incidence of aneuploidy.

Fig 2 shows percentage of cells in the $S$ fraction of the cell cycle determined by flow cytometer in different histological subtypes. The percentage of cells in $\mathrm{S}$ phase increased significantly the higher the histological grade ( $p<0.0001$, Kruskal Wallis test). The median $\mathrm{S}$ fraction in the low, intermediate, and high grade lymphomas was $1.0(0.0$ to 10.0$) \%, 4(0.4$ to $35) \%$, and $27(4.6$ to 56$) \%$, respectively. Fig 3 shows examples of cell cycle analysis of the three grades of non-Hodgkin's lymphoma. Heterogeneity, with regard to a given histological subtype, was seenin diffuse large cell lymphoma the $\mathbf{S}$ fraction varied from 2.5 to $35 \%$. In 10 aneuploid cases, in which the aneuploid population could be separated from the diploid, aneuploid population had a higher percentage of cells in the $S$ phase of the cell cycle in eight cases. The median $\mathrm{S}$ fraction in lymph nodes showing reactive hyperplasia was $0.5(0-2.2)$ and it was not significantly different from that of low grade lymphomas.

\section{THYMIDINE LABELLING}

The $\left({ }^{3} \mathrm{H}\right)$ thymidine labelling was studied in 115 cases. The labelling index in these cases ranged from $0 \cdot 1$ to 35 . Wide variations in labelling index were observed in different histological grades and subtypes. A strong linear correlation was observed between the $S$ phase values and labelling index $(=0.98)$. The $S$ phase estimated by flow cytometry was consistently 75 (SD 3)\% of the labelling index. Fig 4 shows distribution and median values of the labelling index in various histological subtypes.

\section{Discussion}

The availability of flow cytometry has made the measurement of DNA content of cells relatively simple and quick. Abnormal DNA content represents strong evidence of the neoplastic nature of a cell population. In patients with early stage mycosis fungoides and non-diagnostic histology the finding of aneuploidy on flow cytometry acts as a diagnostic aid that facilitates an early diagnosis. ${ }^{13}$ Moreover, it has been shown that aneuploidy is indicative of a poor prognosis in certain tumours, such as those of breast, ${ }^{14}$ bladder, ${ }^{1516}$ prostate, ${ }^{16}$ and ovary. ${ }^{14}$ In $\mathrm{T}$ cell lymphomas there is a small group of cases with aneuploidy and a high $\mathrm{S}$ fraction that seem to have an especially favourable prognosis, with a high proportion of durable complete responses. ${ }^{17}$

A varying incidence of aneuploidy has been reported in non-Hodgkin's lymphoma-from 29 to $80 \% .{ }^{13679}$ In our study the incidence was similar to that reported in a recent series comprising a large number of cases and in which the same criterion was used for the definition of aneuploidy. ${ }^{7}$ In our study the incidence of aneuploidy increased from low to high grade lymphomas. In another recent study, in which the lymphomas were subclassified according to the International Working Formulation, the incidence of aneuploidy in various histological subtypes was similar to that found in our study. ${ }^{1}$ The variable incidence reported could be due, in part, to the different criteria used in the diagnosis of DNA aneuploidy and to the inclusion of different proportions of various histological grades of non-Hodgkin's lymphoma.

A wide range of labelling index values was observed among different histological subtypes of non-Hodgkin's lymphoma and even within a given histological subtype. This reflects the heterogeneity of non-Hodgkin's lymphoma with regard to the growth fraction, even within the one histological subtype. The technique of $\left({ }^{3} \mathrm{H}\right)$ labelling, however, is laborious and is being replaced by $\mathrm{S}$ fraction estimations using flow cytometry, a quick and accurate method of quantifying the number of cells in DNA synthetic phase. On the basis of ours and other published studies, there seems to be a good correlation between the percentage of $S$ phase cells and the histological subtypes of malignant lymphoma. The low grade lymphomas had a lower percentage of cells in S phase than the intermediate and high grade lymphomas. It has been recently reported that patients with nonHodgkin's lymphoma with less than $5 \% \mathrm{~S}$ fraction have a significantly better survival than those with greater than $5 \% \mathrm{~S}$ fraction cells. ${ }^{8}$ The percentage of cells in the $S$ phase of low grade lymphomas was not found to be significantly different from that of reactive lymphoid hyperplasia.

The calculation of $S$ fraction is often difficult in patients who have a mixture of neoplastic and nonneoplastic tissues. In such cases isolation of neoplastic populations by labelling with monoclonal antibodies 
specific for tumour associated antigen or in the case of B cell lymphoma, surface immunoglobulin, may provide more specific kinetic information. ${ }^{18}$ The results of our study suggest that non-Hodgkin's lymphomas are heterogeneous, with regard to cytokinetic features, and that they can be delineated into several subgroups on that basis. Moreover, there seems to be heterogeneity, even within a given histological subtype. The prognostic value of these variables will be determined after enough cases have accumulated in each subgroup and after an adequate period of follow up.

We are grateful to Dr J Matthews for statistical analysis, Mr S Hunter, and Mr P Hutchinson for technical help, and Ms K Borchert for excellent secretarial help.

\section{References}

1 Srigley J, Barlogie B, Butler JJ, et al. Heterogeneity of nonHodgkin's lymphoma probed by nucleic acid cytometry. Blood 1985;65:1090-6.

2 Hattori T, Hosokawa Y, Fukuda M, et al. Analysis of DNA ploidy patterns of gastric carcinomas of the Japanese. Cancer 1984;54:1591-7.

3 Barlogie B, Rober MN, Schumann J, et al. Flow cytometry in clinical cancer research. Cancer Res 1983;43:3982-7.

4 Wijkstrom H, Granberg-Ohman I, Tribukait B. Chromosomal and DNA patterns in transitional cell bladder carcinoma. Cancer 1984;53:1718-23.

5 Diamond LW, Braylan RC. Flow analysis of DNA content and cell size in non-Hodgkin's lymphoma. Cancer Res 1980; 40:703-12.

6 Costa A, Mazzini G, Del Bino G, Silvestrini R. DNA content and kinetic characteristics of non-Hodgkin's lymphoma: determined by flow cytometry and autoradiography. Cytometry 1981;2:185-8.
7 Shackney SE, Levine AM, Fisher RI, et al. The biology of tumour growth in the non-Hodgkin's lymphomas. A dual parameter flow cytometry study of 220 cases. J Clin Invest 1984; 73:1201-14.

8 Braylan RC, Diamond LW, Powell ML, Hasty-Golder B. Percentage of cells in $\mathrm{S}$ phase of the cell cycle in human lymphoma determined by flow cytometry. Cytometry 1980;1:171-4.

9 Diamond LW, Nathwani BN, Rappaport H. Flow cytometry in the diagnosis and classification of malignant lymphoma and leukemia. Cancer 1982;50:1122-35.

10 The non-Hodgkin's lymphoma Pathologic Classification Project: National Cancer Institute sponsored study of classifications of non-Hodgkin's lymphoma. Summary and description of a working formulation for clinical usage. Cancer 1982;49:2112.

11 Taylor IW, Millthorpe BK. Evaluation of DNA fluorochromes staining techniques and analysis for flow cytometry. $J$ Histochem Cytochem 1980;28:1224-32.

12 Hidderman W, Schumann J, Andreef M, et al. Convention on nomenclature for DNA cytometry. Cytometry 1984;5:445-6.

13 Wantzin GL, Larsen JK, Christensen J, et al. Early diagnosis of cutaneous T-cell lymphoma by DNA flow cytometry on skin biopsies. Cancer 1984;54:1348-52.

14 Hedley DW, Friedlander ML, Taylor IW. Application of DNA flow cytometry to paraffin embedded archival material for the study of aneuploidy and its clinical significance. Cytometry 1985;6:327-33.

15 Klein FA, Herr HW, Whitmore WF, et al. An evaluation of automated flow cytometry (FCM) in detection of carcinoma in situ of the urinary bladder. Cancer 1982;50:1003-8.

16 Frankfurt OS, Slocum HK, Rustum YM, et al. Flow cytometric analysis of DNA aneuploidy in primary and metastatic human solid tumours. Cytometry 1984;5:71-80.

17 Shackney S, Levine A, Fisher A, et al. The differential effects of aneuploidy and $S$ fraction on patient survival and complete response rate in non-Hodgkin's lymphomas of B and T ce $\mathbb{P}$ type. Proceedings of ASCO 1985;4:C-78.

18 Braylan RC, Benson NA, Nourse VA. Cellular DNA of huma neoplastic B-cells measured by flow cytometry. Cancer Res. 1984;44:5010-6.

Requests for reprints to: Dr SK Juneja, Haematology Research Unit, Cancer Institute, 481 Little Lonsdale Street, Melbourne, Victoria 3000, Australia. 